\title{
APPLICATION OF 3S TECHNOLOGY TO LAND CONSOLIDATION IN CHERNOZEM REGION OF CHINA
}

\author{
a case study of Hulun Buir
}

\author{
Boqi Wang ${ }^{1}$, Nan $\mathrm{Li}^{2}$, Wei $\mathrm{Li}^{1}$, Jinmin $\mathrm{Hao}^{1, *}$ \\ ${ }^{1}$ College of Resources and Environmental Sciences, China Agricultural University, Beijing, \\ P. R. China 100193 \\ ${ }^{2}$ College of Engineering, China Agricultural University, Beijing, P. R. China 100083 \\ * Corresponding author, Address: College of Resources and Environmental Sciences, China \\ Agricultural University, Beijing 100193, P. R. China, Tel: +86-10-62732077, Fax: +86-10- \\ 62733568,Email:jmhao@cau.edu.cn
}

\begin{abstract}
The chernozem has high productivity, most of which is located in Northeast of China. Considering the restrictions of land use and terrain and meteorological conditions, soil erosion and degradation often result in lower agricultural output than expected. Land consolidation is served to consolidate parcels and to enlarge holdings as well as included provisions such as irrigation, drainage infrastructure, in order to improve land leveling and productivity potential. Therefore, the purpose of our research is to maintain the productivity of cultivated land and to enhance the conservation of water and soil by way of land consolidation, with two case studies in Hulun Buir in Inner Mongolia Region. Northeast of China. Our research integrated Geographic Information System (GIS), Remote Sensing (RS) and Global Position System (GPS), and also introduced an optimized method which could save earthwork and reduce soil erosion risks with a holistic perspective considering cultivated land, water, road and forests land. The results showed that by using the optimized method, comparing to total plane method, the earthwork decreases by $3 / 4$ and $7 / 8$; for slant method, the reduced earthwork is $1 / 2$ and $1 / 3$. Meanwhile, this optimized method can also significantly reduce risk of surface land removal in chernozem land This paper concluded that we should use 3S technology to find soil erosion area, and implement amending local topography method during cultivated land consolidation in chernozem area.
\end{abstract}

Keywords: land consolidation, GIS, chernozem region, Hulun Buir, China

Please use the following format when citing this chapter:

Wang, B., Li, N., Li, W. and Hao, J., 2009, in IFIP International Federation for Information Processing, Volume 293, Computer and Computing Technologies in Agriculture II, Volume 1, eds. D. Li, Z. Chunjiang, (Boston: Springer), pp. 145-153. 


\section{INTRODUCTION}

Land, given by nature, is human beings' valuable resource and asset. Land resources are limited and non-renewable. It not only ensures human beings' life and development (Hao Jinmin, 1996, 2007; Zhu Daolin, 2000; Lars D.et al., 1992), but also bears great responsibility of national food security. In order to relief status of cultivated land decrease, China has begun to develop land consolidation since 2001, aiming to improve agricultural productivity and ensuring dynamic balance in whole nation's total cultivated land. Land consolidation is served to consolidate parcels and enlarge holdings and included provisions such as irrigation and drainage infrastructure to improve land leveling and soil. It has been achieved initial successes in China (Fan Min, 2006). However, the land consolidation project ignored the ecological construction.

At present, there are still few studies for land consolidation on chernozem region in China. This region has unique natural conditions and ecological environment, special ways of production and management. Recently China proposed the important issues of Northeast revitalization planning. It emphasized ecological comprehensive control of black soil area (i.e. area with black soil, chernozem and meadow soil), strengthening comprehensive control on soil and water loss, perfecting protection forest system around cultivated land, recovering grassland vegetation, modifying and fertilizing black soil, preventing non-point source pollution.

Chernozem was formed by meadow grassland vegetation through humus accumulation process of calcium carbonate eluviation and deposition under half moist climate. It is a kind of soil which surface is with black humus, but lower soil layer is with calcium horizon or with lime reaction (Lü Yizhong et al., 2006). The area of chernozem region in China is 134.216 million $\mathrm{hm}^{2}$ (Liu Chunmei et al., 2006 ), mainly distributed in southwest part of Heilongjiang province, west part of Jilin province, northwest of Liaoning province and Hulun Buir City in eastern part of Inner Mongolia autonomous region. It means that chernozem region is mainly distributed in song-nen plain, both east and west side of Daxing'anling, and Songliao Divide region. (Fig.1.)

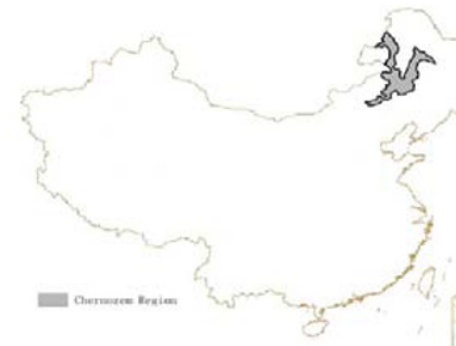

Fig.1. Chemozem major regional distribution of China 
This paper selected agricultural land consolidation, on two typical landforms (valley plain, low mountain and hill) in Hulun Buir, as empirical studies. We studied agricultural land consolidation with holistic perspective of field, water, and road and protection forest comprehensively in chernozem region. Then we introduced an optimized design method of agricultural land consolidation compared to total plane method, which was prevalent across the whole nation. Finally we proposed some advices on agricultural land consolidation for chernozem region of China.

\section{BACKGROUND OF THE STUDY AREA}

Study area A and B respectively located in Yakeshi and Erguna, both in Hulun Buir in eastern part of Inner Mongolia autonomous region (Fig.2.). Study area A, in Yakeshi, is situated at Long. $121^{\circ} 08^{\prime} 42^{\prime \prime}-121^{\circ} 11^{\prime} 11^{\prime \prime}$ E, and Lat. $49^{\circ} 13^{\prime} 20^{\prime \prime}-49^{\circ} 15^{\prime} 15^{\prime \prime} \mathrm{N}$. Its total area is $1148.384 \mathrm{hm}^{2}$. Micro topography of area $\mathrm{A}$ is plain, and average gradient is $1.2 \%\left(<2^{\circ}\right)$, smaller in east-west direction. Annual average temperature is $-2.2^{\circ} \mathrm{C}$, annual average rainfall is $402.4 \mathrm{~mm}$.

Study area B, in Erguna, is situated at Long. $119^{\circ} 26^{\prime} 07^{\prime \prime}-119^{\circ} 28^{\prime} 52^{\prime \prime}$ E, and Lat. $50^{\circ} 12^{\prime} 11^{\prime \prime}-50^{\circ} 13^{\prime} 23^{\prime \prime} \mathrm{N}$. Its total area is $995.423 \mathrm{hm}^{2}$. Micro topography of area B is low mountain and hill, and north-south average gradient is below $6.0 \%$, east-west average gradient is below $5.0 \%$, but fluctuation in south landform is relatively varied from $2-8^{\circ}$. Annual average temperature is $-3.2^{\circ} \mathrm{C}$, annual average rainfall is $497.5 \mathrm{~mm}$. Table 1 , Table 2 show the soil properties of study areas (Pu Demao, 1993).

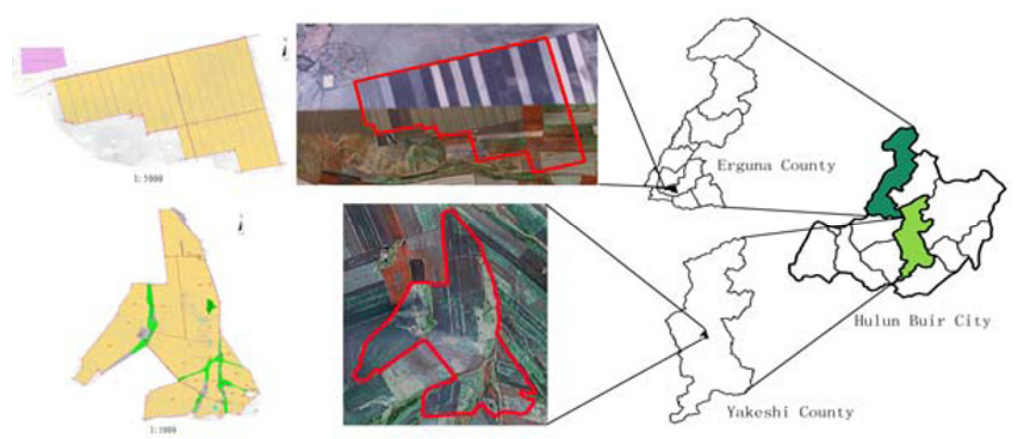

Fig. 2. Land Use Map and Location of Land Consolidation study areas

Per capita cultivated land in whole Erguna county is $0.19 \mathrm{hm}^{2}$, and in Yakeshi county is $0.30 \mathrm{hm}^{2}$ (Yakeshi Bureau of Statistics network, 2005). In the two study areas, per capita cultivated land is above $15 \mathrm{hm}^{2}$., which means 
per capita cultivated land in study areas is very rich, but labors for agriculture is relatively few. So in order to solve the problem of labor force, agriculture producing mainly depends on farm economic organization to implement mechanized farming; meanwhile, it greatly improves agricultural production efficiency.

Both of above study areas are farm management mode, mainly depending farm economic organization on producing, with intensive mechanized farming. For the mechanical way of cultivate, and unsustainable management until now, the utility of chernozem nutrient is off balance, and the quality of soil is decreasing continuously which causes soil erosion, soil degradation and land desertification. This problem widely exists in China chernozem region.

Tab. 1. Meteorological characteristics of study area A and B

\begin{tabular}{ccccccccc}
\hline & $\begin{array}{c}\text { Average } \\
\text { temperature accumulated } \\
{ }^{\circ} \mathrm{C}\end{array}$ & $\begin{array}{c}\geq 0{ }^{\circ} \mathrm{C} \\
\text { temperature } \\
{ }^{\circ} \mathrm{C}\end{array}$ & $\begin{array}{c}\geq 10 \\
\text { accumulated } \\
\text { temperature } \\
{ }^{\circ} \mathrm{C}\end{array}$ & $\begin{array}{c}\text { Annual } \\
\text { rainfall } \\
(\mathrm{mm})\end{array}$ & $\begin{array}{c}\text { Annual } \\
\text { evaporation } \\
(\mathrm{mm})\end{array}$ & $\begin{array}{c}\text { Frostless } \\
\text { period } \\
(\mathrm{d})\end{array}$ & $\begin{array}{c}\text { Annual } \\
\text { average } \\
\text { wind speed } \\
(\mathrm{m} / \mathrm{s})\end{array}$ & $\begin{array}{c}\text { Soil } \\
\text { freezing } \\
\text { depth } \\
(\mathrm{m})\end{array}$ \\
\hline $\mathrm{A}$ & -2.2 & 2404.9 & 1815.6 & 460.0 & 1107.5 & 96.4 & $1.8-3.6$ & 2.7 \\
$\mathrm{~B}$ & -3.1 & 2216.0 & 1767.0 & 397.5 & 1197.7 & 95.0 & $2.1-2.5$ & 3.0 \\
\hline
\end{tabular}

Tab. 2. Soil characteristics of study area A and B

\begin{tabular}{cccccccccc}
\hline AREA & $\begin{array}{c}\text { Organic Matter } \\
\text { content } \\
(\mathrm{g} / \mathrm{kg})\end{array}$ & $\begin{array}{c}\text { Total } \\
\text { nitrogen } \\
(\mathrm{g} / \mathrm{kg})\end{array}$ & $\begin{array}{c}\text { Phosphorus } \\
(\mathrm{g} / \mathrm{kg})\end{array}$ & $\begin{array}{c}\text { Potassium } \\
(\mathrm{g} / \mathrm{kg})\end{array}$ & $\mathrm{pH}$ & $\begin{array}{c}\text { Soil bulk } \\
\text { destiny } \\
\left(\mathrm{g} / \mathrm{cm}^{3}\right)\end{array}$ & $\begin{array}{c}\text { Soil full } \\
\text { field Water Thickness } \\
\text { content } \\
(\mathrm{cm})\end{array}$ & $\begin{array}{c}\text { Soilope } \\
\text { gradient }\end{array}$ \\
\hline $\mathrm{A}$ & 53.1 & 2.5 & 1.15 & 22.8 & $5.5-6.8$ & 1.25 & 30 & 55 & $<2^{\circ}$ \\
$\mathrm{B}$ & 49.1 & 2.3 & 1.16 & 21.2 & $5.6-7.0$ & 1.35 & 20 & 50 & $2-5.8^{\circ}$ \\
\hline
\end{tabular}

\section{DATA AND METHODS}

\subsection{Data acquisition}

We used GPS and total-station to get enough special information and land use data of area A and B, including: dividing line of different land-use and study areas, contour line with $5 \mathrm{~m}$ elevation difference, data of 4260 elevation points, data of other facilities, surrounding water area and rural residential area's boundary. (Zhang Xianfeng et al., 2000; Xu Saocuo et al., 1998; Shen Qinghua et al., 2005; Li Yinong et al., 2005) Besides, we also used remote sensing images of the study areas. The images were taken from institute of remote sensing in Chinese academy of sciences, and social economic data were selected from documents and yearbooks. 


\subsection{Methods}

According to "Engineering design of land consolidation" (Chinese Ministry of Land and Resources Centre, 2005), and based on natural and cultivated conditions in study area A and B, we used GIS software, remote sensing image and elevation data for spatial analysis. Then we studied on the impact of simulation by using different methods of land formation on the area to determine the optimal design method of land consolidation.

In this section we introduced an optimized method for land consolidation. For comparison, these following characteristics should be taken into account:

(1) After leveling up by plane method, the field is so flat that it is not good for the subsurface drainage needs of the chernozem arable area. The study areas are gentle slope and hilly plain micro-topography, respectively. Flat land formation of the land consolidation will increase the amount of earthwork; through the undulating terrain in the larger region after finishing the land will have a height differences between the fields, and will bring some inconvenience for the mechanized operations.

(2) After leveling up by slant method, the design slope of field which is exactly consistent with the irrigation direction, can not lead to a slow flow speed, irrigation water (or rain, snow and ice melt water) on the ground after would exacerbate erosion of cultivated land.

(3) Optimized amending local topography method can make the internal field flat, and achieve a high degree of consistence within neighboring field blocks. Considering climate and terrain conditions and farming methods of the study area, amending local topography method would be more appropriate for the chernozem land consolidation. (Fig.3)

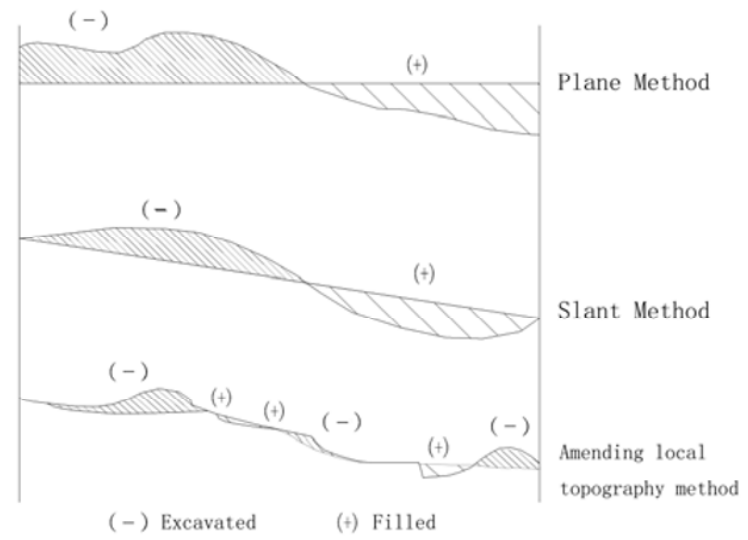

Fig.3. Land Consolidation Methods 


\section{CULTIVATED LAND FORMATION RESULTS}

Most cultivated blocks in our study areas are less gentle slope, the paper mainly selected the A study area more than $3{ }^{\circ}$ and $\mathrm{B}$ study area greater than $5{ }^{\circ}$ (mild erosion of soil surface area)(Department of Water and Soil Conservation, 1997). We used the spatial data which were obtained through GPS, field investigation and remote sensing image to map the land use maps of study areas A and B. By using 3D maps, slope charts and the $20 \times 20 \mathrm{~m}$ DEM (Digital Elevation Model) (Fig. 4, 5), which were formed by Surfer and ArcGIS, the program of land consolidation earthwork calculation was optimized based on AutoCAD.

The optimization process is as follows: the ArcGIS was used to generate a slope map, determining the region to be consolidated (Fig. 6, 7). In addition, by using the planning maps superimposed with the study area rule grid DEM map as well as the study area slope map, the selecting longitudinal slope maps of planning field blocks (slope too big ups and downs of the regional field blocks) were obtained. Based on the principle of incompletely changing original topography, the excessively concave convex field, according to whole longitudinal slope direction of field blocks, can be drafted. Through filling the lowlands, low-cutting highlands method, longitudinal slope maps of planning field blocks were formatted. And then by filled longitudinal slope surface area and multiply the field blocks width, we measured filling of the earthwork.

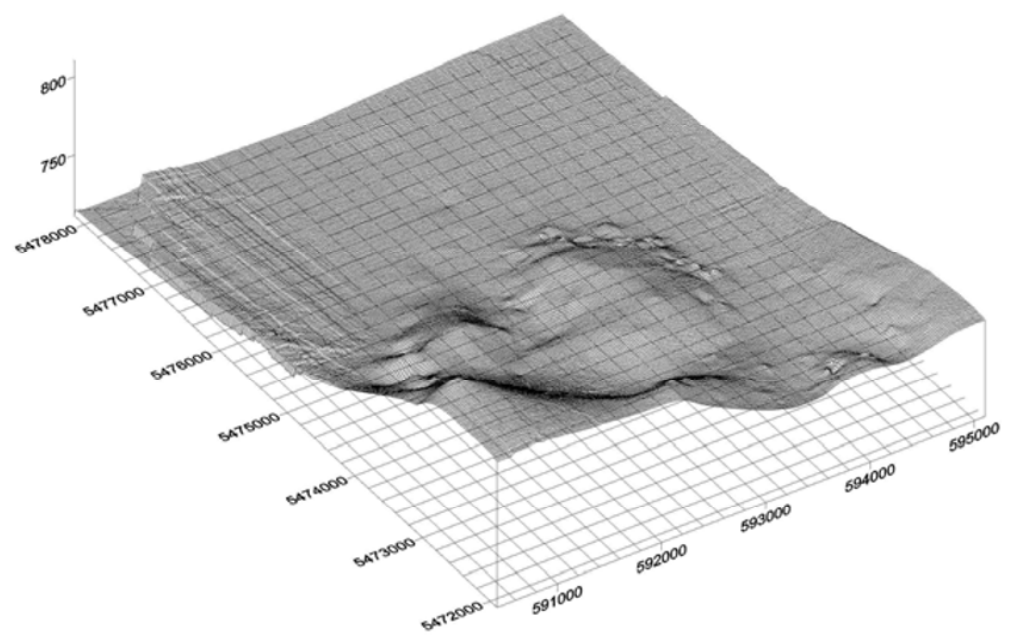

Fig.4. Digital Elevation Model of Study Area A 


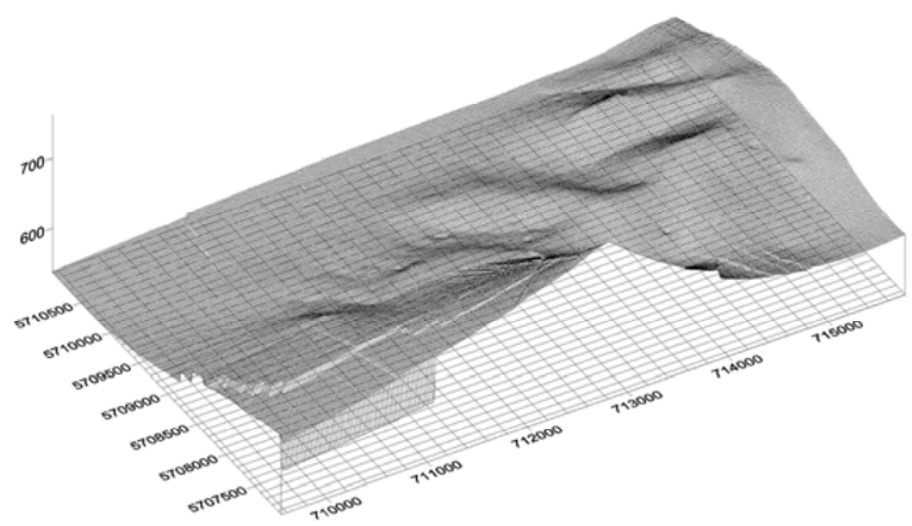

Fig.5. Digital Elevation Model of Study Area B

The result indicated that by using the optimized method, the consolidation works for the earthwork of study area A is $3532000 \mathrm{~m}^{3}$ and $1072000 \mathrm{~m}^{3}$ for study area B. Comparing to calculation results by plane methods, the earth volume decreases by $3 / 4$ and $7 / 8$, and for slope method, the reduced earthwork is $1 / 2$ and $1 / 3$. At the same time, to use optimized method can significantly save the earthwork, reducing the risk of decline in the quality of chernozem land, and this decline due to large-scale removal of surface land. Using optimized revision local topography method to amend the layout can reduce partial soil erosion strength, and so that the height difference of planning cultivated land between field blocks can be narrowed, and it is good for mechanized operations and drainage needs.

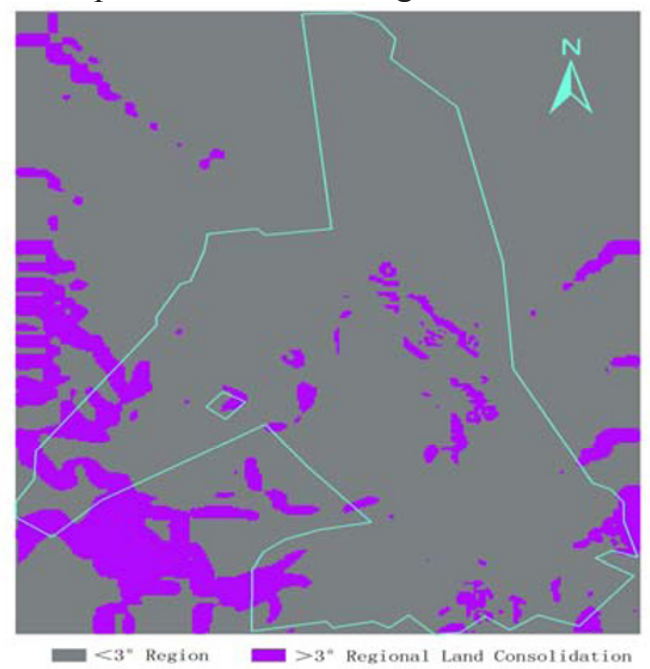

Fig.6. Gradient Map of Study Area A 


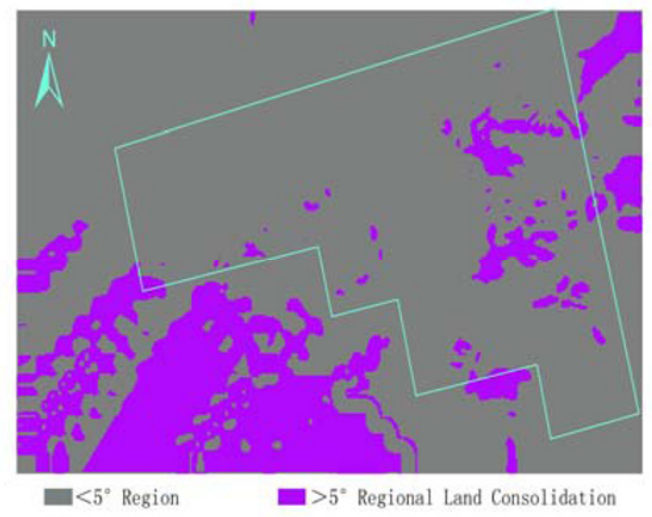

Fig.7. Gradient Map of Study Area B

\section{CONCLUSION}

In Hulun Buir, two land consolidation regions which have different natural condition and the agricultural tillage methods, application of $3 \mathrm{~S}$ technology to the land leveling methods has been discussed. We used $3 \mathrm{~S}$ technology to design land consolidation project and calculated earthwork, and adapt to the local mechanization production method to avoid the soil quality decline and soil erosion caused by large-scale removal of land and site preparation. Also amending local topography method can save the earthwork, and save the investment of land consolidation. It is useful to apply the method land consolidation to extend chernozem region of China.

So we suggest the method of amending local topography. The conclusion is expected to provide the effective method and the suggestions for land consolidation of the chernozem area.

\section{ACKNOWLEDGEMENTS}

The first authors wish to gratefully acknowledge Mr. DeBiao Meng from Beijing in P. R. China, Dr. Quanzhi Yuan and Miss Linli Zhang from China Agricultural University for their dedicative and enthusiastic revision to this paper. The first author is grateful to the China Agricultural University for providing him with pursuing a PhD degree at the College of Resources and Environmental Sciences. 


\section{REFERENCES}

Cui Wenhua, Yu Caixian, Mao Guowei, Changes of fertility of cultivated land in Lingdong black soil zone of Hulunbuir city, Journal of plant nutrition and fertilizer, 2006, 12(1): 2531(in Chinese)

Cui Yan, Gao Mingfu, Wang Kai, Initial Analysis on hadatu farmland shelter creating in Hulun Buir City , Inner Mongolia Forestry Investigation and Design, 2002, 25(3): 46-47(in Chinese)

D. Lars, B Wagayehu, Soil and water conservation decision behavior of subsistence farmers in the Eastern Highlands of Ethiopia. Ecological Economics, 2003, 46: 437-451

Department of Water and Soil Conservation, Ministry of Water Resources of the People's Republic of China, Standard of Classification on the Soil Erosion(SL190-96), China WaterPower Press, 1997: 2-16(in Chinese)

Fan Min, Review and prospect of land consolidation in China. Journal of Agricultural Engineering, 2006, 22(10): 246-251(in Chinese)

Hao Jinmin, Land-use control, China Agricultural Science and Technology Press, 1996: 15 (in Chinese)

Hao Jinmin, Sciences of Land Use Planning. China Agricultural University Press, 2007: 1928(in Chinese)

Li Yinong, Xu Di, Li Fuxiang, Application of GPS technology in agricultural land levelling survey, Journal of Agricultural Engineering, 2005. 21(1): 66-70(in Chinese)

Liu Chunmei, Zhang Zhiyi., Discussion of the Area and Distribution of Black Soils in Northeastern China, Heilongjiang Agricultural Science, 2006, (2):23-25 (in Chinese)

Lü Yizhong, Li Baoguo, Soil science. China Agricultural Science and Technology Press, 2006: (in Chinese)

Ministry of Land and Resources Centre, Land arrangements engineering design. China's personnel Press, 2005: 58-64(in Chinese)

$\mathrm{Pu}$ Demao, Local Chronicles of Erguna Right Banner, Inner Mongolia Cultural Press, 1993: 26-81(in Chinese)

Shen Qinghua, a number of technical problems of GPS-RTK applications, Pearl River modern mapping, 2005, 128(6): 4-7(in Chinese)

Sun Xianbo, Lou Jimin, the influences of low temperature and anoxia of reservoir deep water on irrigated crops, Zhejiang Water Science and Technology, 2000, 2:8-9 (in Chinese)

Wang Guoguang, Wang Guoxian, Chen Chengming, Soil of Inner Mongolia, 1994. Beijing:(in Chinese)

$\mathrm{Wu}$ Youkun, the application of float-type water intake on the small reservoir irrigation, Technical supervision of water, 2006, 6:29(in Chinese)

$\mathrm{Xu}$ Saocuo, Zhang Haihua, Yang Zhiqiang, GPS survey principle and its application, Wuhan Technical University of Surveying and Mapping Press, 1998: (in Chinese)

Yakeshi Bureau of Statistics network. Yakeshi national economic and social development statistical bulletin in 2005 [EB / OL]. Http://tjj.hlbe.gov.cn/ykstjjwy/tongjishuju2.htm

Yang Yi., Development of water-saving irrigation in drought-stricken areas according to local conditions, Jilin Water Conservancy, 1999, 197(6): 40-42(in Chinese)

Zhang Xianfeng, Cui Weihong, Using Differential GPS Technology To Update Land Use Data, Earth sciences progress, 2000, 15(5): 609-613(in Chinese)

Zhu Daolin, Land Management. China Agricultural Science and Technology Press, 2000: 510(in Chinese) 